\title{
Connected Giving: Ordinary People Coordinating Disaster Relief on the Internet
}

\author{
Cristen Torrey, Moira Burke, Matthew Lee, Anind Dey, Susan Fussell, Sara Kiesler \\ Human Computer Interaction Institute \\ Carnegie Mellon University \\ \{ctorrey, moira.burke, matthew.lee, anind, sfussell, kiesler\}@cs.cmu.edu
}

\begin{abstract}
The Internet is widely valued for distributing control over information to a lateral network of individuals, but it is not clear how these networks can most effectively organize themselves. This paper describes the distributed networks of volunteers that emerged online following Hurricane Katrina. Online communities responded to the disaster by facilitating the distribution of donated goods from ordinary people directly to hurricane survivors. These "connected giving" groups faced several challenges: establishing authority within the group, providing relevant information, developing trust in one another, and sustaining the group over time. Two forms of computer-mediated connected giving were observed: small blog communities and large forums. Small blog communities used a centralized authority structure that was more immediately successful in managing information and developing trust, but over time, blog communities were difficult to sustain. Larger and more decentralized forums had greater difficulties focusing the community's communication and developing trust but sustained themselves over a long period of time.
\end{abstract}

\section{Introduction}

Hurricane Katrina flooded $80 \%$ of New Orleans and left four million residents of the southern United States in need of assistance [1]. The magnitude of the disaster overwhelmed institutions normally responsible for providing relief, such as the Red Cross and the Federal Emergency Management Agency (FEMA). Displaced residents of the city of New Orleans waited days for shelter, clothing, and financial aid. Meanwhile, people around the United States felt compelled to help. Some used Internet bulletin boards to offer jobs, services, and financial assistance to hurricane evacuees. When the Red Cross specifically discouraged "in-kind" donations of goods due to sorting and delivery overhead, website owners created online spaces to promote "connected giving." Connected giving allowed people with goods to donate (such as clothing, tools, or diapers) to connect with people in the disaster area [11]. Donors saw their distributed efforts as an appropriate complement to the distributed needs of those affected by the disaster. They saw gaps left by large, institutionalized organizations that could be filled by a peer-to-peer approach. Individuals with no training in disaster relief found one another through online communities and organized the distribution of an ad hoc collection of resources. People appropriated the technologies that were available to them-forums, bulletin boards, blogs, and personal websites - to coordinate a massive grassroots response to the disaster.

Our initial observation revealed two forms of computer-mediated connected giving: small blog communities and large forum communities. Small communities benefit from the strong relationships between members; these strong ties make cohesive, trusting groups. Large communities have the advantage of more resources, larger networks of participants, and diverse information [10]. Weak ties within large communities link people to new sources of information while the information from strong ties - which are often based on interpersonal similarity - may be redundant.

Some connected giving communities used a moderator to establish authority and group norms, but others distributed authority equally to members and established group norms by consensus. The Internet is widely valued as a technology that connects people directly to one another. For example, Wikipedia allows the public to author a continually evolving encyclopedia and relies on its members to monitor one another's contributions [4]. Usenet communities collectively define group norms by co-authoring a frequently asked questions file [14]. Open source software communities grant commit privileges to a subset of participants in order to maintain quality [21]. Slashdot uses thousands of moderators to rate the information the group receives [16]. The absence of a single, centralized authority does not imply that these groups lack organizational structure. Communities that distribute authority must establish group norms as well, but they do so collectively. 
In order to investigate the successes and challenges of small blog communities and large forums, we sampled four representative sites. This research did not attempt to quantify the number of boxes shipped to the disaster zone. Instead, we observed the communication in four online communities to understand how groups function under these conditions. Connected giving groups faced several challenges: establishing authority within the group, providing relevant information, developing trust in one another, and sustaining the group over time. We found that small blog communities utilized a centralized authority structure that appeared more immediately successful in managing information and developing trust, but over time, community blogs were difficult to sustain. Without a centralized authority, large forums had greater difficulties focusing the group's communication and developing trust but managed to sustain themselves over a long period of time.

\section{Challenges of connected giving}

A connected giving community includes both donors and hurricane survivors, a mix of people offering and seeking help. Donors post offers and include their contact information. Hurricane survivors tell their stories and request specific items for their families. Other members offer logistical information, such as which zip codes are not flooded and open for postal deliveries.

We observed connected giving communities dealing with challenges common to groups of many kinds. Connected giving communities struggled to establish authority to standardize norms and procedures, to provide access to the information that motivates member participation, to develop trust among members, and to sustain the activity of the group. Connected giving communities after Katrina faced these challenges with a unique sense of urgency. The pressing need for disaster relief attracted large numbers of potential participants in a very short time and increased the likelihood of organization and communication failure. Groups coordinating disaster relief online face additional hardships beyond those of face-to-face groups. Working remotely, teams take longer to complete tasks [12] and have more disagreements than teams working locally [28].

\subsection{Establishing authority}

A centralized authority exists when decisions are made by one or a few individuals, such as a moderator or blog owner. Centralization helps achieve two goals: quality control and accountability. A moderator establishes interaction norms and standard operating procedures for the site. Contributions from visitors are subject to review by the moderator to determine appropriateness. In some cases, a moderator may establish interaction norms simply through leading by example, but moderators may actively edit or delete posts of community members as well.

Decentralized authority structures are those in which decisions are made locally, distributed to members of the community. Decentralization has an advantage in making use of local expertise and on-the-scene contextual knowledge. However, no single person is accountable for problems.

In decentralized online communities, the burden of developing interaction norms and standard operating procedures occurs through open discussion. Some decentralized communities use voting systems to influence the behavior of other members, such as allowing members to flag inappropriate posts. Heavily flagged posts are removed.

In theory, there is no right answer as to which authority structure is better for an online community. Centralized authority supports smooth coordination, accountability, and consistency. Decentralized authority supports speedy action and local expertise.

\subsection{Accessing information}

In order for joint work to be successful, people must have access to the right information and people at the right times. Individuals often join online communities to exchange information [25]. In context of urgent disaster relief, the need for access to information becomes even more important. Potential donors want their offers to be accepted; requestors want to be heard.

\subsection{Developing trust}

People coordinating disaster relief work under time pressure with complete strangers, and so trust is critical. In this context, trust is the willingness to be vulnerable beyond rational risk, based on the expectation of positive action from another person [17]. In online communities without time pressure, members establish relationships over time; trust develops through their interaction history [3]. When a trusted relationship is established, that individual becomes a conduit to other trusted contacts. Trust can be assisted by the involvement of a trusted third party; if the third party is trusted, then trust can be extended through that individual [30].

Under these emergency conditions, however, a kind of swift trust may be at work. Research on swift trust suggests that strangers attempting to develop temporary groups may rely upon simple, category-based judgments - such as similar socio-economic status or religion - to build trust [20]. Individuals also identify another person as a member of a trusted group and 
transfer trust to that person [24, 29]. Group members also bond and identify with one another. Bonding to other group members can occur through frequent interaction, mutual disclosure, and interpersonal similarity [18].

In the present research, one method for measuring trust was to observe its absence. Conflicts related to interpersonal trust within the group can be highly noticeable, amplified by third-party gossip [5]. Suspicious or distrustful behavior within the group may have destructive effects beyond those of trust-building events [26].

\subsection{Sustaining group activity}

Retaining existing members and recruiting new ones is critical; to achieve these goals, groups must display a record of activity and encourage member contribution [2]. Visible content helps newcomers develop expectations about group benefits, and interaction leads to increased commitment of existing members [22]. When people receive replies to their messages, they are more likely to post again; the effect is particularly strong for newcomers [15]. The benefits of recruitment and retention do have their limits, however. Groups must maintain a size appropriate to their goals. Though large groups have access to more resources [19] and diverse information [9], they also face coordination problems [27], potential for conflict [7], and decreased contribution [13].

\section{Method and sample}

Thirteen connected giving communities were observed for a period of six months. Four representative communities were selected for study in more detail and a portion of their website communication was coded for further qualitative analysis. The four communitiestwo blogs and two forums-were selected because they focused on in-kind goods donation and had observable activity over the focal period.

Katrina relief sites were gathered with a snowball sampling method, beginning with Google searches for Hurricane Katrina relief sites, and then following links from posts on Craigslist, searching Friendster and Orkut for "Hurricane Katrina" and "New Orleans," and following website references from newspaper stories and blogs. Our initial sample of websites included several different formats for communication (see Table 1). Blogs and forums are examples of websites that were repurposed by their owners to be used for coordinating relief efforts.

In this paper, we focus on the use of forums and blogs by connected giving communities because these types of communities were the most prevalent. The appropriation of blogs and forums is particularly interesting because their creation and use has become accessible to those without any technical training. In contrast, databases and wikis generally require hosting one's own server. Another compelling aspect of blogs and forums is that they facilitate visible communication between participants, an essential element for online community development. The interaction on forums and blogs is structured by the format of the communication and the size of the group.

Table 1. Formats of relief sites

Website URL (http://) Format forums.ebay.com/forum.jspa?forumID $=1000000$ Forum 000

forums.craigslist.org/?forumID $=52 \quad$ Forum

www.nola.com/forums/reachingout Forum

groups.google.com/group/Katrina-Hub Forum

www.citizenactionteam.org Forum

www.reliefspark.org Database

www.katrinasangels.org Database

gracedavis.typepad.com/katrinablog Blog

wheretosenddonationsforkatrina.blogspot.com Blog

beenthere.typepad.com Blog

katrinahelp.blogspot.com Blog

katrinahelp.info Wiki

www.projectbackpack.org Wiki

A forum is a facility on the Internet used for holding discussions. Participants start new discussion threads and reply to existing threads. Forums are commonly hosted by high-traffic websites. Participants go through a minimal registration process to post and reply to messages. Messages in forums are typically organized in a threaded structure to allow for replies to messages to be easily tracked (see Figure 1).

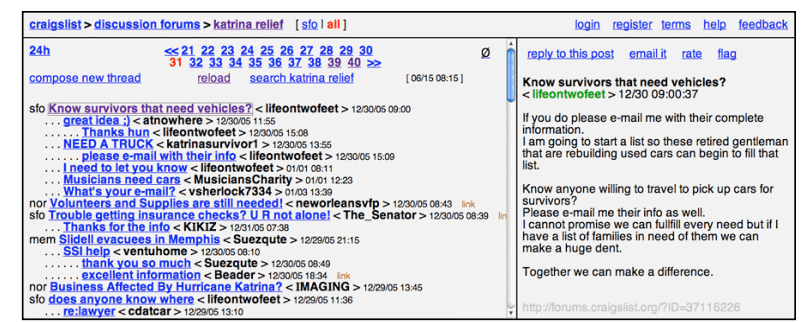

Figure 1. Threaded structure of forums

A blog is a website where messages are posted by date in reverse chronological order (see Figure 2). Blogs generally have a dedicated group of readers and participants. Unlike forums, blogs do not allow visitors to make a post on the blog, but they often allow readers to comment in response to a blog author's post after a simple registration process, usually requiring a username and email address. Blog readers do not have the ability to address another reader's comment directly; additional comments are appended to the list. 


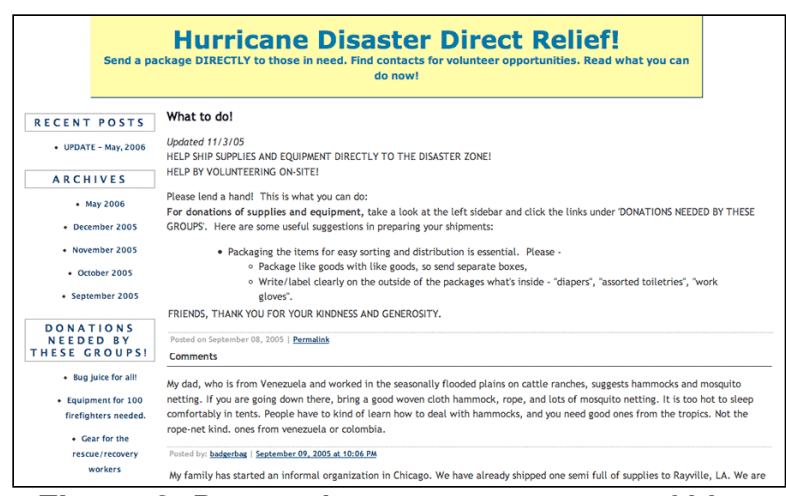

Figure 2. Post-and-comment structure of blogs

Online communities exist in many different sizes. Some communities support the communication of a small circle of close friends, while others support thousands of people in a single group. Assessing a group's true size is difficult because there is an unknown number of potential "lurkers," people observing the group without actively participating [23]. It is possible, however, to compare group size on the basis of active participation and define group members as those who post to the website.

\subsection{Websites Sampled}

Communication format and group size did not vary independently in these communities. Blogs were small and forums were large. We selected four representative websites, two of each type, with observable activity focusing on in-kind donations of relief goods (see Table 2). From these four websites, we collected communication activity between August 28, 2005 and February 25, 2006. For the blogs, content consisted of posts made by the blog owner and comments left by readers. For the forums, content consisted of threads and the associated responses.

Table 2. Connected giving community sample

$\begin{array}{cccc}\text { Community } & \text { Format } & \text { Group } & \text { Participating } \\ \text { Been There } & \text { Blog } & \text { Small } & \text { Members } \\ \text { Direct Relief } & \text { Blog } & \text { Small } & 92 \\ \text { Craigslist Katrina Relief } & \text { Forum } & \text { Large } & 3,549 \\ \text { Nola.com Reach Out } & \text { Forum } & \text { Large } & 2,119\end{array}$

The Been There blog focused on parenting. In response to Hurricane Katrina, the blog authors posted an entry asking readers to offer clothes, toys, or other supplies to victims in the comments section of the post. Visitors to the site who were in need posted comments about their backgrounds and specific requests. The blog authors occasionally marked the offers and requests that had been fulfilled by editing the comment. An overwhelming response from readers offering and requesting goods motivated the blog authors to launch a new version of their site solely dedicated to matching people in need with donors. The Been There blog had different sections for posting offers of goods, posting requests for goods or information, telling stories, and connecting donor families with needy families. Most of the communication appeared in the long list of comments.

The Direct Relief blog was also created by a longtime author of a personal blog. After contacting a woman coordinating donations to shelters and churches in the disaster area, the blog author launched Direct Relief to publicize what donations were most needed and where they could be shipped. The blog author subsequently added a section dedicated to connecting people with families affected by the hurricane and coordinating the donation of goods to meet their longerterm needs. The owner-authored content consisted of contact information and lists of items needed by shelters or families. Most of the requests for goods were contributed by the blog owner and appeared in the main posts. Visitors read through the list of requested goods and mailed items to the given address. The comments section of each blog post allowed readers to ask questions or post information about others that needed help, the overall donation process, and goods they had to offer. Most of the messages offering and coordinating goods were contributed by the blog readers and appeared in the comments.

The Craigslist Katrina Relief forum was set up shortly after the disaster to allow people to discuss anything related to the hurricane relief effort. In its threaded discussion format, any visitor who registered could reply to an existing thread or start a new thread. Katrina Relief forum is one of many discussion forums found in a popular online classifieds site.

Nola.com's Reach Out was hosted on a New Orleans newspaper site. It was a threaded discussion forum where anyone who registered could start new threads or post replies. Reach Out focused on helping people connect with New Orleanians to offer assistance in donations, housing, and jobs.

3.1.1 Website activity. For each of the four sites, we gathered statistics about the communication and membership activity over time. We counted the number of new threads and messages per week, and calculated how many times each participant posted.

Posting statistics for the four sites were broken down into two categories: posts made by the site owner and those from the public. The proportion of coordination content contributed by the blog author gives a rough indication of how much authority the moderator exerted in the community. To investigate the emergence of community leaders - core contributors without administrative control over the site-the frequency of repeat posters within the community was counted. 
3.1.2. Content coding. A coding scheme was developed to analyze the communities' task and social content (see Table 3). A single post was coded with any combination of the two codes, such as "other relief info" and "distrustful." The task content codes addressed the community's ability to access information, and the social content codes addressed the development of trust in the community. The authors coded a random subset of the posts on each site. Our sample included 250 messages selected at random from each website, for a total of 1,000 messages. To assess inter-rater reliability, two of the authors coded a subset of 50 messages from each site, for a total of 200 messages. Cohen's kappa [6] for task content was 0.77 , social content was 0.76 .

\section{Table 3. Content coding scheme}

$\begin{array}{ll}\text { Task Content: } & \text { Social Content: } \\ \text { Access to Information } & \text { Development of Trust } \\ \text { Donation Info } & \text { Supportive } \\ \text { Other Relief Info } & \text { Distrustful } \\ \text { Off-Task } & \text { Neither }\end{array}$

3.1.2.2. Access to information. The primary activity of these communities is coordinating information. One person may know where goods are needed; another may have the needed goods. Both kinds of information must be accessible. The distraction of off-topic chatter was a concern for creators of these communities. One website (not included in our detailed analysis) specifically informed participants to keep their communication focused on disaster relief:

We do understand you're wanting to post and talk to each other and to be a community based board. Under normal circumstances we would be doing cartwheels to see this occur. The problem we face on this board is if the front page is full of chat threads when a disaster situation is in effect important information that people need would be lost among the OT [off-topic] threads.

For each site we measured access to on-task information, that is, how easy it would be for people to find the necessary information to fulfill their goals. We coded the sample posts and identified those that contained "on-task" information such as requests, offers, and confirmations of shipping or receiving:

I have used clothes in very good condition for boys 2-6 years, boots, shoes and toys. Also, nice stroller and crib w/mattress for the Katrina victims. Email me for more info. God Bless all, my heart and thoughts are with you.

On-task posts also included information about the general relief effort such as updates from the disaster area, contact information for shelters or families that required assistance, suggested links to other online or offline resources, and instructions for shipping:

can anybody help explain to me why my mother is not receiving any financial help at all from the red cross? I have spoken to quite a few people who are in much better financial situations than she is and have received 2 installments from the red cross. any insight would be helpful.thanks.

Seems that Amazon will ship, they just say it will take about 10 days.

Off-topic posts were not directly related to the task of donating goods, e.g. chat about personal lives, rants about politics or beliefs, or advertisements:

So so true. If you are poor you usually get the shaft no matter where you are in this world. A powerful industrialized nation or the third world.

\section{goodnight all I am turning in}

3.1.2.3. Development of trust. For each site, we measured how participants identified themselves with the group by coding posts for the presence of supportive content. It included praise for the accomplishments of the group, thanking other participants for their (potential) contributions, or displays of positive affect toward the group:

Hey guys, Glad to help. Would love to hear the story if possible. Thanks for keeping an eye out for the ones that truly need help. You are both amazing to me! Hugs!

Thank you for all that you are doing to get the word out and get help!

For each site, we coded posts for the presence of distrust, including questions of the accuracy of information or the authenticity of an individual:

and just for the record, I WAS scammed by one that posted on this board. However, all it did was make me more cautious.

[name], at this particular time, I really think that the last thing we need is someone yanking people's chains just for the hell of it. Back off.

Posts about government officials or scam websites were not coded as distrust here. A post fell into the distrust coding category only if it questioned the legitimacy of a participant or the content of the online community.

\section{Results}

The following is a description of trends observed in small blog communities and large forums in their respective abilities to establish authority, provide access 
to information, develop group trust, and sustain activity over time.

\subsection{Establishing authority}

Although generally it is possible for blog authors to distribute authority equally to all members, we did not find evidence of equality in our sample. As previously discussed, the format of the communication on a blog lends itself to one or more central moderators supported by a group of readers. Readers interact by posting comments, but the blog author has ultimate responsibility for the site content and procedure.

The moderators' activity on the two blogs differed. For Been There and Direct Relief, the moderators contributed $8 \%$ and $71 \%$ of all communication to the discussions, respectively. The majority of the content of Been There came from the community whereas the majority of the content on Direct Relief came from the blog author.

The small blog communities established authority by focusing on the personality and reputation of the moderator(s). Neither of the moderators we observed needed to explicitly dictate group norms; their communication behavior as well as their encouragement of others' behavior was enough to establish a standard for group communication.

The large forums did not use moderators to establish authority. Though the administrators of the sites-Craig Newmark and the New Orleans Times-Picayune newspaper-are the ostensible leaders, their presence was negligible or completely absent. A few discussions of authority, including decisions for prioritizing and coordinating donations, were present in the forums, but we observed no clear consensus on these issues. Given the sheer volume of new threads appearing every day on the forum, it would be difficult for any single committed member to provide direction to the group. In the first two weeks, the Katrina Relief forum received over seven thousand messages. A volunteer that sought to directly moderate a forum of that size would have little time for coordinating disaster relief.

\subsection{Accessing information}

The number of messages varied greatly between large forums and small community blogs, and all of the sites received a large percentage of messages in the two weeks after the hurricane. Table 4 shows the number of messages at each site in the first two weeks as a percentage of the total messages posted in the entire sixmonth period. This means that connected giving communities had the most resources-people and information - in the very beginning of their development, in some cases before the communities had established procedural norms.
Table 4. Number of messages in first two weeks as percentage of total activity

$\begin{array}{ccccc}\text { Community } & \text { Format } & \begin{array}{c}\text { First Two } \\ \text { Weeks }\end{array} & \begin{array}{c}\text { \% of } \\ \text { Total }\end{array} & \begin{array}{c}\text { Total } \\ \text { Messages }\end{array} \\ \text { Direct Relief } & \text { Blog } & 34 & 21 \% & 159 \\ \text { Been There } & \text { Blog } & 369 & 43 \% & 868 \\ \text { Katrina Relief } & \text { Forum } & 7,257 & 44 \% & 16,505 \\ \text { Reach Out } & \text { Forum } & 3,104 & 72 \% & 4,299\end{array}$

None of the websites we observed had official policies for propriety. Nonetheless, there were de facto norms in the actual content. We looked at the distribution of on-task messages, those focused on the donation of goods, in order to compare the effort expended by members of different communities to access the information they needed.

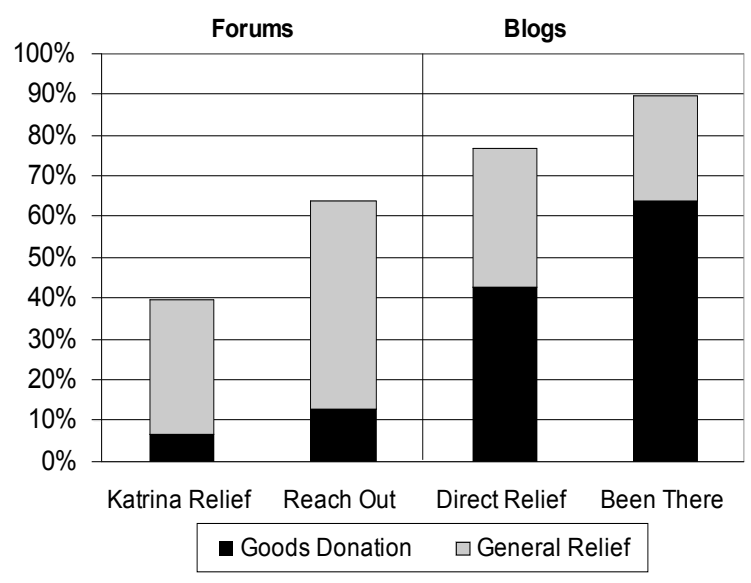

Figure 3. Percentage of on-task messages

As shown in Figure 3, the moderated blogs (Direct Relief and Been There) had a higher concentration of task-specific information. The blogs were created with the goal of coordinating the donation of goods, and the messages largely reflect the task-focused nature of the communication. In contrast, the forums were created for general Katrina relief discussion. These forums had far fewer donation-relevant posts, but they also contained a lower percentage of on-task information than the blogs. We did not formally analyze the remaining message content on the forums because the present analysis focused on donation coordination, but we observed a large amount of political and social debate. Participants on one of the forums immediately identified this type of communication as a distraction and wanted off-task posters to take their discussion to another board in order to make the relief information more accessible. One person wrote, "I did post several times in the first few days after Katrina, when an idiotic troll posted every few minutes." Trolls are posters that seek to create trouble; their messages are also called "flamebait" [8]. Because the forums had no moderator, no individual had the authority to enforce a single content norm. The 
group had to agree over time on appropriate uses of the board. On the Katrina Relief Forum, members flagged posts, identifying inappropriate ones. If enough members flagged a post, it could be removed, but it took time.

\subsection{Developing trust}

The social challenge for these distributed groups is the problem of developing trust with strangers. In all of the communities we sampled, participants had to create an online identity to post a message. Most identified themselves with unique screen names, although some used their real names and addresses. We observed people expending effort verifying their identities to one another. They sometimes emailed scans of their driver's licenses to members who questioned their identities; some offered their FEMA identification numbers or even their social security numbers in forum posts as evidence of their identity. Different communities required different strategies to develop trusting, working relationships with one another.

4.3.1. Trust developed through interaction history. Visible histories of interaction led to trust in the blogs. Blog moderators posted inspiring stories about the donated goods reaching their destinations and thankyou messages from recipients. The impact of the group's work and the legitimacy of the blog author were clear. The visibility of the collective effort motivated participants and it also helped establish the blog owner's reputation, providing information to newcomers about the groups' trustworthiness.

The reputation of the blog moderator was then used to transfer trust to the moderator's contacts; the moderator functioned as a trusted third-party. When a potential recipient was introduced by the moderator, community members trusted whomever the moderator vouched for. One blog poster wrote, "This is from [the moderator], therefore it is real and has been verified." In another instance, one moderator requested goods for her son's coworker's family. Even though the information was removed several times from its source, the reputation of the moderator was so strong that community members trusted the recipients and organized donations for them.

Communities that utilized a distributed authority structure could not rely on the visibility and resultant trust in a single moderator. Participants in forums still needed to establish interaction-based trust, but they had a more difficult time establishing credibility. One participant invited another to investigate her reputation: "You can ask multiple people on this board and many others that can back my reputation." As a result of the sheer number of participants, members of forums had to work harder to remain visible to one another.
Participants vouched for each other explicitly: "A is someone you can trust ...she has lots of links and places if you need info she is like a library!!....and a very good woman!!!" However, the large volume of communication made specific testimonials less salient.

Forum participants made themselves visible by actively responding to others' questions and threads. Many threads contained direct dialogue between posters, and some members posted dozens of times (see Figure 4). On the Katrina Relief Forum, there was a core group of around twenty individuals that posted to the forum over a hundred times each; one individual posted over nine hundred times.

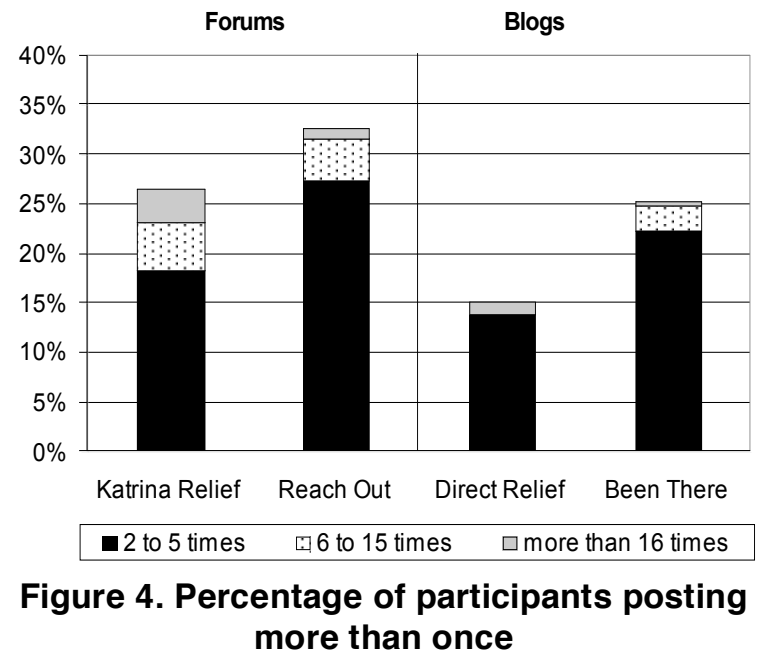

4.3.2. Trust developed through group membership. When working with strangers, a common way of developing trust is through group membership. Trust can be transferred to an individual simply by identifying them as a member of a trusted social category. Connected giving participants often casually identified themselves in the process of making an offer: "I just recently became a stay at home mom, so I have suits or casual clothes." Participants also identified their collaborators by group membership, referring to the "supermom-on-the-ground" or "she's a Steel Magnolia." On the blogs we studied, community members seemed to be fairly similar to the blog moderators and to each other. Members often identified themselves as mothers.

As a mother of 3, my heart goes out to the many displaced people of the Gulf Coast...I and a lot of my friends and neighbors want to help. I am a member of or know others who are active in several mothers' groups in my area. We all feel a very real NEED TO HELP!

Members also wanted to help those who were like them. One donor considered her own experience trying to find the right formula for her child and felt compelled to help others in the same predicament. 
I have a child who has struggled with severe reflux/dairy/soy allergy, and I have some of his very costly (\$50/can) formula left over that is still good. Children who need this formula and don't get it can suffer SERIOUS physical pain! These children cannot tolerate your typical milk or soy based formula, or even the special broken down formulas. I know what my baby went through (horrendous screaming for MONTHS), and I am picturing these few special babies who are being fed normal formula because that is all their poor mothers can get their hands on.

In comparison, the diversity of participants on large forums may have inhibited some of the benefits of this kind of self-disclosure. When participants on forums disclosed personal information, especially politics or religion, the disclosure was as likely to create conflict as it was to create trust.

In addition to establishing trust on the basis of offline categorical identities, membership in the online community itself translated into trust because a group identity formed around the participants themselves. For all four of our sample communities, we coded the number of times participants said supportive things to one another: "You guys rock," and "This is a great idea." There was a large difference between the moderated blog communities and the forums. Roughly $25 \%$ of blog messages in our sample contained group encouragement; this may have translated into a more salient group identity. The samples of messages from the forums contained approximately 7\% support posts. Forums could not rely on trust in a single authority, and the lower frequency of supportive posts as compared to the blogs may indicate that the strength of their identification to the group was lower as well.

4.3.3. Evidence of distrust. We found few instances of suspicion or interpersonal conflict on either of the moderated blogs we observed. Likely due to the moderator presence and the subsequent development of group identity, blogs showed little distrust. Members recognized that there were some people taking advantage of the generosity of donors; one member asked those requesting donations to send "a full sentence about who you are so I can determine if I'm getting spam or a real request." Of course, participants in blogs may have chosen to verify the trustworthiness of recipients over email, rather than communicate publicly on the blog.

In contrast, approximately $5 \%$ of the forum messages sampled contained accusations and distrust. Examples of distrust were primarily suspicions of falsified stories. you do not know me personally but $i$ had read your postings and was organizing a group of people at my business to help you, but was warned by people on this forum that my help would be better directed elsewhere. people seem not to trust you.

Indeed, some members went to significant lengths to research and monitor members of whom they were suspicious. One member warned, "The one thing that we ask when we offer our help is that you be HONEST with us. If you are NOT honest we WILL find out." There were also more general messages discouraging the donation of goods to unknown people. The posts included links to news stories about Internet scams and online auction listings of previously donated items.

The forums are self-policing, so there was no official moderator to make a decision about potential wrongdoing. When someone on the board was challenged, often there was a public discussion on the board about the disagreement, but there was rarely a definitive outcome. Participants had to simply agree to coexist in the community.

Regardless, we obviously have nothing to offer each other, as we disagree on certain aspects of the ethics of helping. I wish you the best and trust that all will be revealed in its proper time. Until then, everyone has the right to trust, not trust, believe, question, admire, like or dislike whomever they please.

The atmosphere of suspicion was discouraging to those doing volunteer work. Several members posted farewell messages, informing others they were unwilling to participate any longer.

first off $i$ will say this is my last post on here. . . it is just too much going on here it is so hurting to see what is going on . . . sorry we have to come here and see all the distrust by ones who are to help .my heart goes out to the real ones on here.

It is difficult to quantify the precise effect that the distrust messages had on the development of trust and subsequent social coordination of the forums. The level of suspicion on the forums was not an obstacle that the blog communities faced.

\subsection{Sustaining communication activity}

For each site, we counted the number of new posts over time to identify which sites sustained group activity. As illustrated in Figures 5 and 6, all websites experienced an initial spike of activity in the first one or two weeks after the disaster. Activity waned in the weeks that followed. 


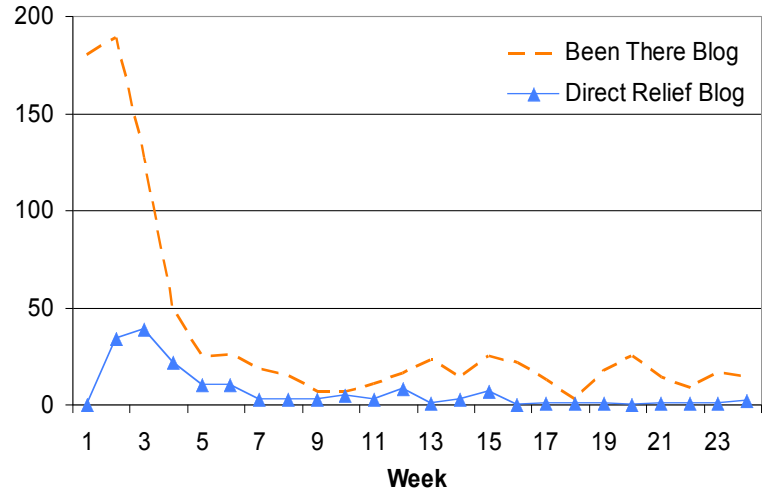

Figure 5. Number of Posts - Blogs

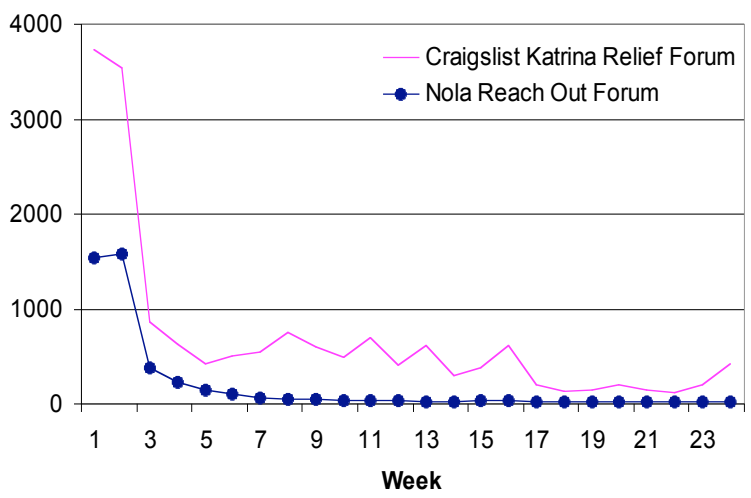

Figure 6. Number of Posts - Forums

Of the four sites we studied, only the Craigslist Katrina Relief Forum, a large community with decentralized authority, remained active six months after the disaster. After the same period, the two blogs exhibited little activity. Comparing the two blogs, we found that activity at Direct Relief, where the owner provided most of the content, extinguished more quickly than Been There, where the community provided the majority of the content.

\section{Discussion}

At the outset of this study, we assumed that a decentralized authority structure would better support speed for channeling relief where it was urgently needed. We expected that a large, distributed network of people would have the information and resources to best cope with the quickly changing situation. The results demonstrate an important tradeoff between small, moderated groups and large, decentralized groups that has consequences for how trust is established and the sustainability of the community.

The presence of a moderator in the small blog communities seemed to address the challenges of providing information and developing trust quickly. The strength of the moderator's presence dictated how the group would function and what constituted appropriate content. Blogs afforded high moderator visibility. The history of the group's activity demonstrated the outcome of the group's effort and established legitimacy for the moderator. Participants rallied around their leader creating the potential for trust based on group membership. Unfortunately, moderated groups could not sustain themselves absent the participation of the moderator. Over time, moderated groups were not long lasting; the continued participation of the community was contingent on communication from the moderator. Six months after the disaster, blog communities had very little or no communication.

In contrast, the large forums we investigated did not use a centralized authority structure (a moderator) to establish group norms. Their collective model of authority relied on group consensus and group bonds, which take time to develop. One forum we studied initially appeared less cohesive than the blogs but ultimately lasted longer than all the other communities because ownership of the group was distributed to multiple members. On the other hand, activity in the other forum community dropped to negligible levels a few weeks after the disaster. We speculate that members did not invest the time to create bonds, build consensus, and take collective ownership of the community to shape it into a sustainable resource.

\subsection{Limitations}

The generalizability of this research is limited by the small sample size. The sample comprises a small percentage of overall communication, and only that which was public. For example, it was likely that group members exchanged email directly with one another. Additionally, the size and authority structures of the sites were intertwined. Because we observed neither large blog communities nor small forums in the disaster relief context, we cannot be certain how communication format and group size operate independently of one another.

\subsection{Future Work}

We found that groups using a decentralized authority structure often struggled to create consensus around group norms and group identity. Once consensus was created, the group appeared stable and members committed, but often the process was lengthy and difficult. Could the process of creating consensus be made more efficient, thereby increasing the overall productivity of the group? It seems possible that conflict may be necessary to instigate an evaluation of the group's norms. One forum weathered the conflict that arose and ultimately bonded together; this forum remains active six months after the disaster. The other forum had fewer visible conflicts, and the group never seemed to cohere. Six months later, participation had 
slowed considerably. In future work, we plan to investigate how conflict functions in creating group solidarity and identity. It may not be possible to sustain a community with a decentralized authority structure without responding to a certain amount of conflict. It is possible that when the group is challenged, members either leave or become motivated to stake out an agenda and a group identity. Further analysis of the group's communication may expose a more detailed picture of the mechanisms that establish group norms and create solidarity among members.

\subsection{Conclusion}

Our work on connected giving communities expands the literature by describing the immediate online collaboration of a large number of people on a timecritical task. We found that small blog communities efficiently managed challenges with the help of a moderator, but these communities were not sustained without the moderator's continued participation. The large forums we observed had difficulties managing their content and developing trust. To the extent these challenges were met, large forums were maintained.

\section{References}

[1]__. Red Cross: Hurricane Season 2005 Six-Month Report. http://www.redcross.org/hurricanes2005/6monthreport, 2006. [2] Beenen, G., Ling, K., Wang, X., Chang, K., Frankowski, D., Resnick, P. and Kraut, R., Using social psychology to motivate contributions to online communities. in Computer Supported Cooperative Work (CSCW 2004), (2004), 212-221, ACM Press.

[3] Boon, S.D. and Holmes, J.G. The dynamics of interpersonal trust: Resolving uncertainty in the face of risk. in Hinde, R.A. and Groebel, J. eds. Cooperation and Prosocial Behavior, Cambridge University Press, New York, 1991. [4] Bryant, S.L., Forte, A. and Bruckman, A., Becoming Wikipedian: transformation of participation in a collaborative online encyclopedia. in Conference on Supporting Group Work (SIGGROUP 2005), (2005), ACM Press.

[5] Burt, R. and Knez, M. Third-party gossip and trust. in Kramer, R.M. and Tyler, T.R. eds. Trust in Organizations, Sage Publications, Thousand Oaks, 1995.

[6] Cohen, J. A coefficient of agreement for nominal scales. Educational and Psychological Measurement, 20 (1960), 37-46. [7] Cummings, J. and Kiesler, S. Collaborative research across disciplinary and organizational boundaries. Social Studies of Science, 35, 5 (2005), 703-722.

[8] Donath, J.S. Identity and deception in the virtual community. in Smith, M. and Kollock, P. eds. Communities in Cyberspace, Routledge, London, 1998.

[9] Granovetter, M. Economic action and social structure: the problem of embeddedness. American Journal of Sociology, 91 (1985), 481-510.

[10] Granovetter, M. The Strength of Weak Ties. American Journal of Sociology, 78, 6 (1973), 1360-1380.

[11] Harris, L. Connected giving. Salon.com,

http://www.salon.com

/mwt/feature/2005/09/10/charity/index_np.html, 2005.

[12] Herbsleb, J.D., Mockus, A., Finholt, T.A. and Grinter,
R.E., Distance, Dependencies, and Delay in a Global Collaboration. in Computer Supported Cooperative Work (CSCW 2000), (Philadelphia, PA, 2000), ACM Press. [13] Karau, S. and Williams, K. Social loafing: A metaanalytic review and theoretical integration. Journal of Personality and Social Psychology, 65, 4 (1993), 681-706.

[14] Kollock, P. and Smith, M. Managing the Virtual Commons: Cooperation and Conflict in Computer Communities. in Herring, S. ed. Computer-Mediated Communication, John Benjamins, Amsterdam, 1996.

[15] Lampe, C. and Johnston, E., Follow the slash(dot): Effect of feedback on new members in an online community. in Conference on Supporting Group Work (SIGGROUP 2005), (2005), 11-20.

[16] Lampe, C. and Resnick, P., Slash(dot) and Burn: Distributed Moderation in a Large Online Conversational Space. in SIGCHI Conference on Human Factors in Computing Systems (CHI 2004), (Vienna, Austria, 2004), ACM Press.

[17] Mayer, R.C., Davis, J.H. and Schoorman, F.D. An integrative model of organizational trust. Academy of Management Review, 20 (1995), 709-734.

[18] McKenna, K., Green, A. and Gleason, M. Relationship formation on the Internet: What's the big attraction? Journal of Social Issues, 58, 1 (2002), 9-31.

[19] McPherson, M. The size of voluntary organizations. Social Forces, 61, 4 (1983), 1045-1064.

[20] Meyerson, D., Weick, K.E. and Kramer, R.M. Swift Trust and Temporary Groups. in Kramer, R.M. and Tyler, T.R. eds. Trust in Organizations, Sage Publications, Thousand Oaks, 1996, 166-195.

[21] Mockus, A., Fielding, R.T. and Herbsleb, J.D. Two Case Studies of Open Source Software Development: Apache and Mozilla. ACM Transactions on Software Engineering and Methodology, 11, 3 (2002), 309-346.

[22] Moreland, R. and Levine, J. Socialization in organizations and work groups. in Turner, M. ed. Groups at work: Theory and research, Erlbaum, Mahwah, NJ, 2001, 69112.

[23] Nonnecke, B. and Preece, J., Lurker demographics: counting the silent. in Conference on Human factors in computing (CHI 2000), (2000), ACM Press.

[24] Postmes, T., Spears, R. and Lea, M. The Formation of Group Norms in Computer-Mediated Communication. Human Communication Research, 26, 3 (2000), 341-371.

[25] Ridings, C. and Gefen, D. Virtual community attraction: Why people hang out online. Journal of Computer-Mediated Communication, 10, 1 (2004).

[26] Slovic, P. Perceived risk, trust and democracy. Risk Analysis, 13 (1993), 675-682.

[27] Steiner, I. Group process and productivity. Academic Press, New York, 1972.

[28] Straus, S.G. Technology, Group Process, and Group Outcomes: Testing the Connections in Computer Mediated and Face-to-Face Groups. Human-Computer Interaction, 12 (1997), 227-266.

[29] Turner, J.C. Social comparison, similarity and ingroup favouritism. in Tajfel, H. ed. Differentiation between social groups, Academic Press, UK, 1978, 233-250.

[30] Uzzi, B. Social structure and competition in interfirm networks: the paradox of embeddedness. Administrative Science Quarterly, 38 (1997), 628-652. 